\title{
Traduções de Maquiavel: da Índia portuguesa ao Brasil
}

\section{Apresentação}

\author{
Rodrigo Bentes Monteiro[1]
}

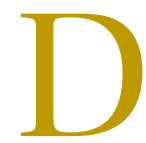

esde há muito, no vocabulário português, "tradução" significa o ato de converter um texto falado ou escrito de um idioma a outro, desejando-se, para o tradutor, um ótimo conhecimento da língua a lhe servir de fonte, bem como uma familiaridade maior com a língua almejada. Conforme o muito citado clérigo luso-francês setecentista Bluteau, as boas traduções não seriam feitas por palavras, mas por equivalências. Para ele, o vocábulo seria ainda uma figura retórica, ao repetir-se a mesma palavra com diferentes sentidos. Alude, então, ao famoso ditado "traduttore, traditore", todavia, ponderando sobre a possível fidelidade dos bons trabalhos. ${ }^{1}$ A acepção de transferir e transformar, relativa ao termo, foi enfatizada em dicionários posteriores da língua portuguesa, ${ }^{2}$ sem prejuízo dos primeiros significados, mas conotando o ato de traduzir como esclarecer o significado de algo. Ou seja, traduzir seria, principalmente, uma interpretação, uma compreensão e uma explicação do que pretende ser entendido. ${ }^{3}$

O dossiê ora apresentado lida com algumas "traduções" do autor Niccolò Machiavelli (1469-1527) e de suas obras, valendo-se não apenas do primeiro sentido apontado, mas também dos outros, em busca de equivalências e/ou interpretações. Em todos os casos, nele procura-se entender certas expressões assumidas por Maquiavel no mundo lusofônico através dos tempos. Essas expressões foram buscadas no império ultramarino português da época moderna, do século XVI ao XVIII, mas também no Brasil independente do século XX.

[1] Departamento de História da Universidade Federal Fluminense (UFF) - Niterói (RJ) - Brasil. E-mail: rodbentes@historia.uff.br

\footnotetext{
'Raphael Bluteau, Vocabulario portuguez \& latino: aulico, anatomico, achitectonico... vols. 8 e 9, Coimbra, Collegio das Artes da Companhia de Jesu, 1712-1728, p. 233-234; 261. Disponível em: <http://www.brasiliana.usp.br/pt-br/dicionario/edicao/1>. Acesso em: 09 de junho de 2014.

2Antonio de Moraes Silva, Diccionario da lingua portuguesa:recompilado dos vocabularios impressos ate agora, e nesta segunda edição novamente emendado e muito acrescentado... Lisboa, Tipografia Lacerdina, 1789, p. 793. Disponível em: <http://www.brasiliana.usp.br/pt-br/dicionario/edicao/2> Acesso em: 09 de junho de 2014.

${ }^{3}$ Antônio Houaiss; Mauro de Salles Villar; Francisco Manoel de Mello Franco (orgs.), Dicionário Houaiss da língua portuguesa, Rio de Janeiro, Objetiva, 2004, p. 2.745.
} 
Nas histórias de Portugal, suas conquistas coloniais e do Brasil, os escritos desse florentino vivenciaram uma trajetória peculiar. Inicialmente, foram lidos com interesse por humanistas durante a expansão lusa na primeira metade do século XVI, com avanços na África, na Ásia e na América nos reinados de D. Manuel I e D. João III. Em um de seus proêmios, Maquiavel ousadamente comparou-se aos navegadores que, então, descobriam o Novo Mundo, fazendo um paralelo entre a sua teoria política e as viagens ultramarinas. ${ }^{4}$ Embora ele não tenha incorporado em seus livros maiores reflexões sobre as novas conquistas então encetadas pelas monarquias ibéricas, após sua morte, suas ideias incidiram na elaboração de textos que dissertavam sobre a natureza e a legitimidade do governo de Portugal nas partes do mundo, principalmente no Oriente. Naquele momento, a censura eclesiástica em Roma e nos países ibéricos ainda não condenara plenamente as obras do secretário florentino. Comparavam-se, então, as epopeias lusitanas aos feitos dos antigos romanos, sendo os Discorsi - cuja tradução para o espanhol fora encomendada por Carlos I e dedicada ao futuro Felipe II de Espanha — uma fonte principal. ${ }^{5}$

\section{Procura-se entender certas expressões assumidas por Maquiavel no mundo lusofônico através dos tempos, no império ultramarino português da época moderna, mas também no Brasil independente do século $X X$}

Sucedeu-se na segunda metade do Quinhentos o tempo dos índices de livros proibidos (romanos, portugueses e espanhóis) e do reforço da ortodoxia católica. Entretanto, paradoxalmente, a pecha de autor proibido e o surgimento do antimaquiavelismo não diminuíram o interesse por essas ideias - ou pelo que elas representavam - no ambiente ibérico e marcadamente português. Nesse mundo de guerras e afirmações de poderes com pretensões mundiais, Il principe - como seria conhecido o opúsculo - e seu autor eram referências incontornáveis. No ambiente católico que formalmente o rechaçou, Maquiavel personificava os vícios da política, frequentemente contrapostos a uma atuação cristã. Mas ele também podia inspirar de forma velada ações tidas como irreprocháveis. Naquele tempo, a má fama do autor de Florença associava-se aos próprios preceitos de uma pérfida razão de Estado. Contudo, suas ideias eram também encontradas em autores formalmente definidos como antimaquiavélicos. ${ }^{6}$

\footnotetext{
"Maquiavel, Comentários sobre a primeira década de Tito Livio: “Discorsi”, 4. ed., Tradução de Sérgio Bath, Brasília, Editora da UnB, 2000, p. 17.

${ }^{5}$ Giuseppe Marcocci, L'invenzione di un impero: politica e cultura nel mondo portoghese (1450-1600), Roma, Carocci, p. 45-88; Giuseppe Marcocci, "Construindo um império à sombra de Maquiavel", In: Rodrigo Bentes Monteiro; Sandra Bagno (orgs.), Maquiavel no Brasil: dos descobrimentos ao século XXI, Rio de Janeiro, Editora FGV; Faperj, no prelo; Helena Puigdomènech, Maquiavelo en España: presencia de sus obras en los siglos XVI y XVII, Madrid, Fundación Universitaria Española, 1988, p. 81-133.

${ }^{6}$ A título de exemplo, o piemontês Giovanni Botero (1544-1617), com especial entrada no mundo ibérico. Luís Reis Torgal; Rafaella Longobardi Ralha (orgs.), João Botero. Da razão de Estado, Tradução de Rafaella Longobardi Ralha, Coimbra, Instituto Nacional de Investigação Científica, 1992; Enzo Baldini (org.), Botero e la 'ragion di stato'. Atti del convegno in memoria di Luigi Firpo (Torino 8-10 marzo 1990), Firenze, Leo S. Olschki, 1992.
} 
Nos séculos XVII e XVIII, em Portugal e no Brasil, surgiram governantes cujas práticas políticas podem ser identificadas como outra vertente de exercício do poder, mais objetiva e temerária, distinta da comumente veiculada aos pactos e mediações característicos de uma monarquia católica respaldada pela filosofia neoescolástica. Em Portugal,essa cultura política foi reforçada na conjuntura da Guerra da Restauração (1640-1668). ${ }^{7}$ Todavia, mesmo nesse meio, não raro administradores e rebeldes incorporaram em seus discursos estratégias de dissimulação, que sabemos não terem sido exclusivas de Maquiavel, mas foram recorrentemente a ele associadas como maquiavelismos. Mais tarde, a participação de nobres portugueses na Guerra de Sucessão da Espanha (1701-1713) constituiu um outro grande momento de internacionalização e contato com ideias excêntricas ao tradicional ambiente reinol lusitano. ${ }^{8}$

Essa breve remissão diacrônica aponta para uma perspectiva teórica e metodológica diferente para o estudo dos governos, ideias e práticas na monarquia portuguesa e em suas conquistas ultramarinas. ${ }^{9}$ Diante desse mundo apenas superficialmente hostil às ideias de Maquiavel, é aconselhável ler as fontes a contrapelo e desconfiar das banais acusações de maquiavelismo, facilmente proferidas a fim de denegrir os inimigos. Esse era um tempo no qual a má reputação do autor florentino contaminava outras formas de dissimulação e de ardil político, existentes desde a cultura clássica. ${ }^{10}$ Abre-se, assim, o leque de possibilidades à heterodoxia e à singularidade, mais frequentes do que as análises modelares dos Estados modernos europeus deixam entrever, para captar esse grande contexto político e cultural - na realidade, multifacetado. Por cópias manuscritas cuidadosamente guardadas e hoje desparecidas, ou por livros proibidos depositados nas bibliotecas monásticas, ou por edições nunca expostas pelos seus detentores, sobreviviam as ideias maquiavelianas, evitando-se, a todo custo, sua vinculação ao maquiavelismo - o que as fragilizaria ante os possíveis acusadores.

Mais adiante, no Brasil já republicano e na esteira da Revolução de 1930, desponta a primeira tradução em língua portuguesa de $I l$ principe, antecedendo em dois anos a sua congênere europeia. Contudo, no país liberto há muito da censura inquisitorial, sobrevivia o tom depreciativo para tratar do que fosse alusivo a Maquiavel. O livro foi publicado por uma editora carioca de perfil socialista para denegrir a escalada ascensional e estrategista de um Getúlio Vargas “maquiavélico", conforme o seu prefácio. Em Portugal, a tradução da mesma obra, conhecida como o "Maquiavel fascista”, com prefácio de Mussolini, fazia também a ponte entre a política então vivida, em pleno salazarismo, e as ideias seminais do florentino quinhentista. ${ }^{11}$

\footnotetext{
־Luís Reis Torgal, Ideologia política e teoria do Estado na Restauração, Coimbra, Biblioteca Geral da Universidade, 1981-1982, $2 \mathrm{~V}$.

${ }^{8}$ David Martín Marcos, Península de recelos. Portugal y España, 1668-1715, Madrid, Marcial Pons, 2014. ${ }^{9}$ Distinta, por exemplo, da promovida por Martim de Albuquerque, Maquiavel e Portugal: estudos de história das ideias políticas, Lisboa, Aletheia, 2007, com base no anterior A sombra de Maquiavel e a ética tradicional portuguesa: ensaio de história das ideias políticas, Lisboa, Faculdade de Letras da Universidade de Lisboa; Instituto Histórico Infante Dom Henrique, 1974.

10Pablo Badillo O'Farrell; Miguel A. Pastor (orgs.), Tácito y tacitismo en España, Madrid, Anthropos, 2013.

"Sandra Bagno, "Il principe nell'area luso-brasiliana e le sue prime traduzioni in portoghese", In: Alessandro Campi (org.), Il principe di Niccolò Machiavelli e il suo tempo. 1513-2013, Roma, Treccani, 2013, p. 219-220.
} 
Voltemos, então, aos vários sentidos da palavra "tradução". Do toscano ou italiano ao português, mas também do político brasileiro contemporâneo, posto como equivalente ao escrito outrora pelo afamado autor no século XVI em relação à prática do poder. Um Maquiavel que falou a outros tempos não poderia, ainda, ter suas ideias e conselhos comparados à atuação de uma personagem coeva, encontrada nos quadros do império ultramarino luso? A correspondência do grande Afonso de Albuquerque, governador da Índia portuguesa no tempo em que era escrito o pequeno livro sobre os principados, mostra o quanto suas preocupações com a conquista e a conservação dos territórios assemelhavam-se aos textos dos Discorsi, Il principe e Dell'arte della guerra, não obstante algumas diferenças em outros tópicos. Albuquerque não leu Maquiavel, mas equivalia-se a suas ideias. Ele seria, portanto, uma sua tradução.

\section{Diante desse mundo apenas superficialmente hostil às ideias de Maquiavel, é aconselhável ler as fontes a contrapelo e desconfiar das banais acusações de maquiavelismo}

É possível perceber também Maquiavel e/ou elementos do maquiavelismo mediante a realização de interpretações, como nos casos do governador-geral do Estado do Brasil no anos de $1660,1{ }^{\circ}$ conde de Óbidos, e do governante de capitania D. Pedro Miguel de Almeida Portugal, então futuro $3^{\circ}$ conde de Assumar, no segundo decênio do Setecentos. Suas ações e escritos apresentam semelhanças com os conselhos proferidos pelo florentino, sobretudo em Il principe. Embora - dados os constrangimentos culturais e políticos já indicados - seja ousado demais atestar cabalmente a leitura feita por esses nobres portugueses dos livros de Maquiavel, seus governos podem ser entendidos como maquiavélicos, pela sobreposição criada na época moderna entre o próprio estereótipo e a sua fonte. Em outras palavras, os elementos de Maquiavel estariam também nesses maquiavelismos que, não obstante, seriam já a sua caricatura. ${ }^{12}$

Sem dúvida, trata-se de um horizonte complexo de investigação, para o qual são importantes os estudos realizados, de matiz filológico ou quantitativo, bem como a sensibilidade e o bom senso das suas análises. Também é fundamental operar com o termo "maquiaveliano" — surgido na Itália do século XX como uma tentativa de remissão às ideias do afamado autor mais despojada de seus estereótipos- e com os outros vários vocábulos derivados de Maquiavel ("maquiavelista”, "maquiavélico", “maquiavelizar” etc.), cujo nome já se costuma

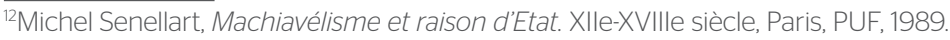


proferir na forma aportuguesada. Tudo isso evidencia sua importante recepção em países de língua portuguesa. ${ }^{13}$

O pequeno dossiê integra-se ao conjunto de realizações pertinentes ao projeto Machiavellismo e machiavellismi nella tradizione politica occidentale (secoli $X V I-X X)$, dirigido por Enzo Baldini, da Universidade de Turim, elaborado com o fito de promover a formação de grupos e colóquios no Ocidente em função da efeméride dos 500 anos da escrita de Il principe, redigido entre fins de 1513 e início de 1514. Desde 2007, cursos, oficinas, jornadas de estudos e um colóquio internacional foram organizados na Universidade Federal Fluminense em parceria com outro evento realizado no Instituto de Ciências Sociais da Universidade de Lisboa -, para perceber o papel das ideias de Maquiavel nos universos português e brasileiro, do século XVI ao presente. ${ }^{14}$ Ao longo desse tempo, lidamos com várias "traduções" e "traições": de livros, ideias e representações. Portanto, os artigos de Ângela Barreto Xavier, Luciano Figueiredo, Rodrigo Bentes Monteiro, Vinícius Dantas e Sandra Bagno constituem uma breve mostra das enormes possibilidades de pesquisa que o campo da história das ideias políticas pode, no momento, descortinar.

Companhia das Índias, junho de 2014.

\footnotetext{
13Sandra Bagno, "Maquiavélico versus 'maquiaveliano"' na língua e nos dicionários monolíngües brasileiros", Cadernos de Tradução, vol. 2, n. 22, Florianópolis, 2008, p. 129-150. Disponível em: <https://periodicos.ufsc.br/ index.php/traducao/issue/view/1121>. Acesso em: 25 de setembro de 2013.

${ }^{14}$ Hypermachiavellism. Disponível em: <http://www.hypermachiavellism.net/>. Acesso em: 19 de janeiro de 2014. Como resultados desses empreendimentos, o dossiê de Gustavo Kelly de Almeida; Bento Machado Mota (orgs.), "Maquiavel dissimulado: heterodoxia no mundo ibérico", 7 Mares. Revista dos pós-graduandos em História Moderna da Universidade Federal Fluminense, vol. 1, n. 1, Niterói, 2012, p. 6-49. Disponível em: <http:/l www.historia.uff.br/7mares/?cat=6>. Acesso em: 24 de fevereiro de 2014, e o livro de Rodrigo Bentes Monteiro; Sandra Bagno (orgs.), Maquiavel no Brasil:dos descobrimentos ao século XXI, Rio de Janeiro, Editora FGV; Faperj, no prelo. Essas inciativastambém vinculam-se ao projeto coordenado por Ronaldo Vainfas, Linguagens da intolerância: religião, raça e política no mundo ibérico do Antigo Regime (Pronex CNPq/Faperj) e ao dirigido por Ângela Barreto Xavier, O governo dos outros: imaginários políticos no império português (1496-1961) (Portugal, FCT). Disponível em: <http://governodosoutros.wordpress.com>. Acesso em: 10 de junho de 2014.
} 